\title{
Variation in Results Due to User Effects in a Simulation with FDS
}

\author{
Nils Johansson* (10, Division of Fire Safety Engineering, Lund University, \\ P.O. Box 118, 22100 Lund, Sweden \\ Madelene Ekholm, The Rescue Service of Östra Götaland, Norrköping, Sweden
}

Received: 10 March 2017/Accepted: 14 August 2017

\begin{abstract}
The results from a round-robin study in which practicing fire safety engineers simulated the same scenario are presented in this paper. The simulation task included the simulation of an $800 \mathrm{~mm}$ heptane pool in a three-room apartment. The participants, representing eight Swedish consultancy firms, simulated the well-specified scenario with FDS 5. The participants received information about the building, the fire mass loss rate and initial conditions. The task was performed a priori, meaning that the participants were not given any experimental or simulation results prior to performing the task. The study shows that there is a variation between the participants in how the input file was specified, the choice of input data and the types of devices used in FDS. The differences in how the fuel and the burner were described were relatively large, which resulted in large differences in mass loss rate and heat release rate. Furthermore, several of the participants made mistakes when the fire was prescribed and this resulted in a variation in the calculated parameters like the temperature increase, which was $300 \mathrm{~K}$ in the fire room and $50 \mathrm{~K}$ to $150 \mathrm{~K}$ in the adjacent rooms. However, the study shows that when the heat release rate and wall boundary conditions were well defined, good temperature predictions could be made.
\end{abstract}

Keywords: Fire Dynamics Simulator (FDS), Simulations, Fire dynamics, Fire engineering, Round-robin

\section{Introduction}

The use of computer models in fire safety engineering has increased rapidly during the last couple of decades. This has made it possible to perform more advanced and detailed analysis than was previously possible. Before the development of computer models in the 1990s, hand-calculation methods were the only option for quantitative fire safety analyses. Now there are several different types of computer models available for fire safety analysis $[1,2]$. The CFD model Fire Dynamics Simulator (FDS) developed by NIST is by far the most used model amongst fire safety engineers and is also often used in research projects. FDS has been evaluated and validated thoroughly and it has been shown to be able to predict smoke spread and smoke gas temperatures well in cubical multi-room geometries [3, 4]. However, it is difficult to model fire spread in FDS, which means that the user often prescribes the fire with a heat release rate.

\footnotetext{
* Correspondence should be addressed to: Nils Johansson, E-mail: nils.johansson@brand.lth.se
} 
The use of advanced fire modelling software requires that the user is knowledgeable in fire dynamics. The advanced computer models are complex and can withhold the user information about the calculation process. This can lead to a so-called "Black box effect" that can result difficulties to critical analyse the results. Therefore, it is important that the user has a fundamental understanding of the underlying fire dynamics of the studied problem. Lamb [5] writes that the understanding of the expected structural behaviour of an element is an essential part of structural modelling and this notion can be translated to the field of fire safety engineering, e.g. by stressing the importance of understanding fire dynamics in order be able to model how smoke will spread in a building.

The background and knowledge of the individual engineer and user will influence the results. It has been seen, in round-robins in other areas than fire safety engineering [6, 7], that there can be large variation between different users even though all received the same task and information. Round-robins amongst fire modellers have also been conducted. An example of this are the studies performed in relation to the Dalmarnock fire tests in Scotland [8], where seven participating teams of experts where asked to perform separate calculations of the same fire scenario. They were given information regarding the presence of fuel in terms of furnishing, room layout and other building properties. The participating teams decided on which fire model to use and estimated the fire growth and fire spread in order to retrieve a heat release rate (HRR) curve to use. When the teams finished their simulations the results in terms of calculated temperatures were collected and analysed by a team of researchers. The participants over-predicted the hot gas layer temperature by $20 \%$ to $500 \%$ when they had no information about the HRR (labelled a priori simulations in the paper [8]), whereas with information about the HRR (labelled a posteriori), which they got at a later stage, the error was reduced to $10 \%$ to $50 \%$. When it comes to local temperatures the a priori simulations over predicted the temperatures by $20 \%$ to $800 \%$, and in the a posteriori simulations the error was reduced it to $20 \%$ to $200 \%$.

The magnitude of the variation can at first glance be considered to be unreasonable large. However, the task that the participants in the round-robin faced was difficult and, without arguing that the variation is reasonable, a large variation should be expected in this type of round-robin. The result from a priori simulations of the Dalmarnock fire tests gives an idea of the variation in the entire process of a fire safety evaluation, by including several parts of the process that will possible cause variation in the result. These parts include: identify the need for analysis, choice of fire model, estimation of heat release rate, simplification of the problem and analysis of the results (see Fig. 1), all of which are in some way related to the previous experience and knowledge of the participating team.

\begin{tabular}{|c|c|c|c|c|}
\hline $\begin{array}{l}\text { Interpretate the } \\
\text { problem and identify } \\
\text { need for analysis }\end{array}$ & $\begin{array}{l}\text { Select } \\
\text { fire model }\end{array}$ & $\begin{array}{l}\text { Simplify problem } \\
\text { and setup } \\
\text { fire model }\end{array}$ & $\begin{array}{l}\text { Define inputs } \\
\text { (Estimate HRR) }\end{array}$ & $\begin{array}{l}\text { Analyse } \\
\text { results }\end{array}$ \\
\hline
\end{tabular}


These parts are interrelated and can be considered to be associated with the variation in results amongst different modellers performing the same task. In the case of the Dalmarnock fire tests the middle three parts of Fig. 1 were, at least in the a priori case, not specified in the instructions to the participants, so different approaches and choices by the participants in these regards is likely to explain the resulting variation. Based on the results it is however difficult to say if any of the mentioned parts will have a greater effect on the final result. More detailed information about the origin of the variation is believed to be desirable, e.g. when developing recommendations or even building codes, in order to reduce the possible variation in fire safety designs of buildings. Furthermore, in some countries (e.g. New Zealand [9] and Sweden [10]) it is now stipulated in recommendations to the building codes what fire growth and maximum HRR to use for different occupancies, which means that the variation as seen in the a priori study in the Dalmarnock fire test are probably unreasonable high in a actual design situation. Therefore, it is considered desirable to study the individually parts of the modelling process (e.g. as described in Fig. 1) in order to get an idea of the size of the variation and user uncertainty associated with the different parts.

In a master thesis, Ekholm [11] gave the task to eight experienced fire safety engineers in Sweden to perform a simulation of a simulation task, with a certain fire model. The participants performed the task a priori, meaning that the simulations were performed blind. The participants were provided with a description of the scenario to be modelled. The participants were given information about the type of fuel and its mass loss rate. However, the participants were responsible for developing appropriate model inputs based on the problem description. The participants were not given any experimental results. The part of the modelling process, as described in Fig. 1, that is in focus in the thesis is "Simplify problem and setup fire model". Results from the thesis is presented and discussed in this paper, however, a full report [11] with additional information is also available.

\section{Method}

The study was conducted in the following steps

- Preparation of the simulation task.

- Invitation to the possible participants.

- Presentation of the simulation task.

- Collection and analysis of data.

After the participants delivered the results the participants undertook a followup survey about the task and quality assurances at the firm and in fire safety design. It was an electronic survey with both open (participant provides a written answer) and closed (multiple choice possible answers) questions. The results from the survey are not reported here; however, the results are available in the thesis [11]. 


\subsection{Participants}

A total of 19 different Swedish fire engineering firms were asked to participate in the study. A total of eleven firms confirmed that they would like to participate; the firms that rejected the invitation did so either due to lack of knowledge and experience in using FDS or due to time constraints. In a later stage three other firms, which previously accepted the invitation, left the study due to lack of resources before delivering any results. Two of these firms, and one of the firms that first rejected, did however participate in the survey. In total, eight firms participated in the simulation task and eleven firms answered the survey.

Each firm participated with an individual engineer. All the participating individuals did have a degree in fire safety engineering and all worked at Swedish engineering firms that deliver fire engineering. The participants mean age was 30 years and they had worked as fire safety engineers for 4 years in average. More background information about the participants is available in Figs. 2 and 3.

The initial ambition in the study was to include practitioners with at least 3 years of working experience; however, this ambition was relaxed in order to include more participants. All participants did have some specific training in CFD (see Fig. 3, right) and everyone had been involved in at least ten design projects (see Fig. 3, left).

\subsection{The Simulation Task}

The task given to the participants was to simulate a specific scenario, which was based on an experimental setup that is used in a laboratory in a Fire Dynamics course at Lund University. The setup consists of a three-room apartment with a floor area of approximately $40 \mathrm{~m}^{2}$ (see Fig. 4). The apartment was located on the first floor in a two-storey building and connected to a stairwell. The walls were made of lightweight concrete (blocks) with a cement-based coating, and the floors and ceilings were made of concrete. A pan with a diameter of $800 \mathrm{~mm}$ filled with approximately $20 \mathrm{~L}$ of heptane was placed in the middle room (room 2) and used
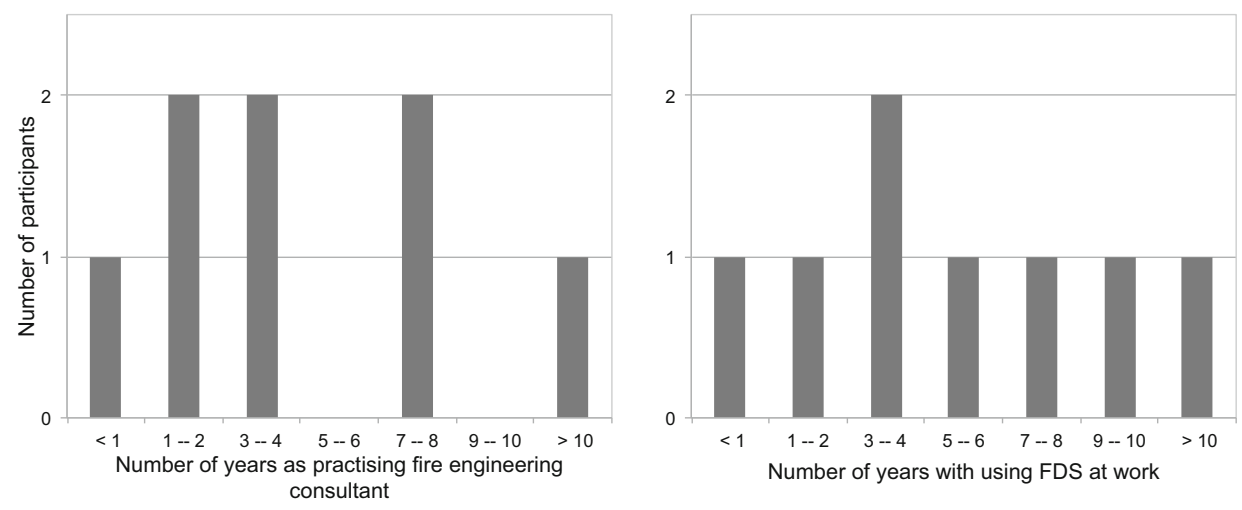

Figure 2. Number of years as practicing fire engineer (left) and number of years using FDS (right) amongst the participants. 

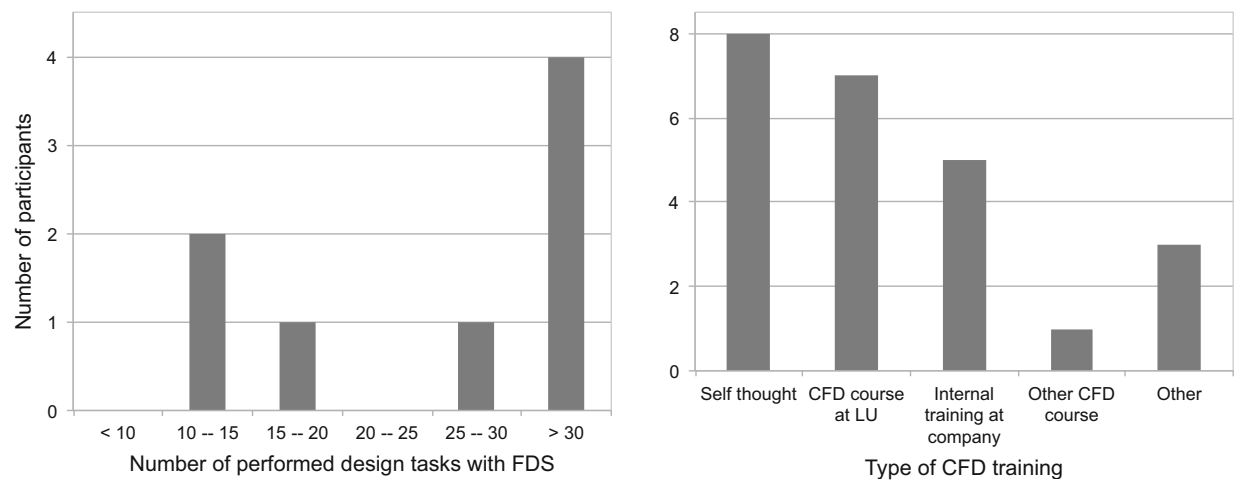

Figure 3. Number of performed design tasks (left) and CFD training (right) amongst the participants.

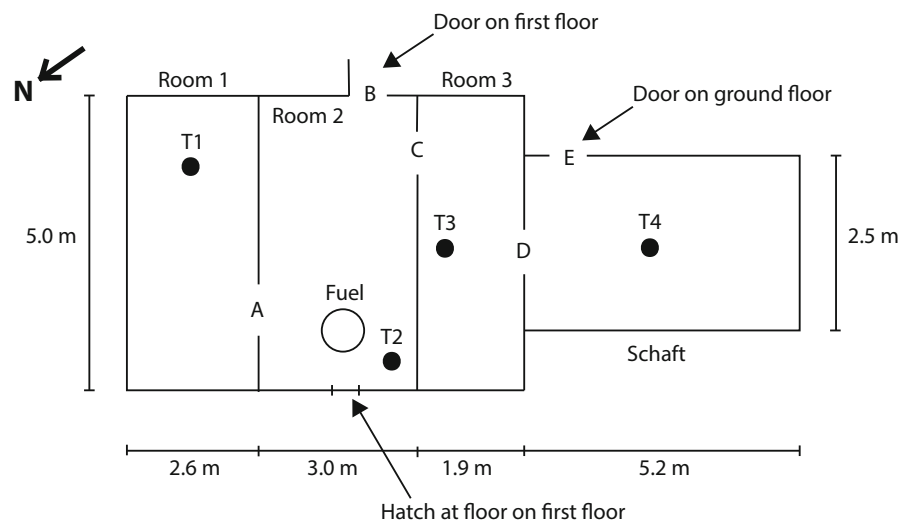

\section{Figure 4. Floor plan of the experimental setup used in the instruc- tions to the participants (translated from Swedish).}

as fire source. The pan was placed on a load cell to measure the mass during the tests and this resulted in that the top of the pan was located $250 \mathrm{~mm}$ above the floor. In the scenario used in the simulation task the only open doors from the apartment was from room 2 to the outside and from room 3 to the stairwell. The interior doors between the rooms and room 3 and the stairwell were open (see Fig. 4). There are experimental data available for a setup that corresponds to the simulation task [12]. However, the participants did not get any information about the results.

The participants were provided with detailed information about initial conditions (e.g. ambient temperature) that may be important. Accordingly, the participants had the potential to mimic the experiment; still, they themselves needed to decide what they wanted to prioritize, consider and simplify. 
There were no possibilities to compensate the participants economically; consequently, the task was simple and well defined in order not to take to much time to perform. Furthermore, the participants did not need to analyse or present the data in anyway, they were only asked to deliver an output file that included a set of pre-defined output parameters.

All participants received the same information concerning the building, the building material, internal dimensions, orientation of the building and the position of the doors. Furthermore, the participants were presented with the position of the thermocouple threes, size of the thermocouples, fire source location, fuel type, as well as the experimentally determined mass loss rate (see Fig. 5). The following environmental conditions were also given in the instructions to the participants:

- Indoor temperature, $-3{ }^{\circ} \mathrm{C}$ (the same for rooms $1,2,3$ and shaft).

- Outdoor temperature, $-8.5^{\circ} \mathrm{C}$.

- Wind speed and direction, $1.3 \mathrm{~m} / \mathrm{s}$ and $340^{\circ}$.

- Humidity, $90 \%$.

- The position of open doors (open $90^{\circ}$ or $180^{\circ}$ ).

- The building is standing free without any nearby buildings.

In order to avoid that the participants would recognize or identify the building, information about where the building was located was omitted. It was stated that no holes or imperfections existed in the walls, which is not entirely true because some minor holes actually exists in the real building and the thickness of the walls deviates at some places from the given values.

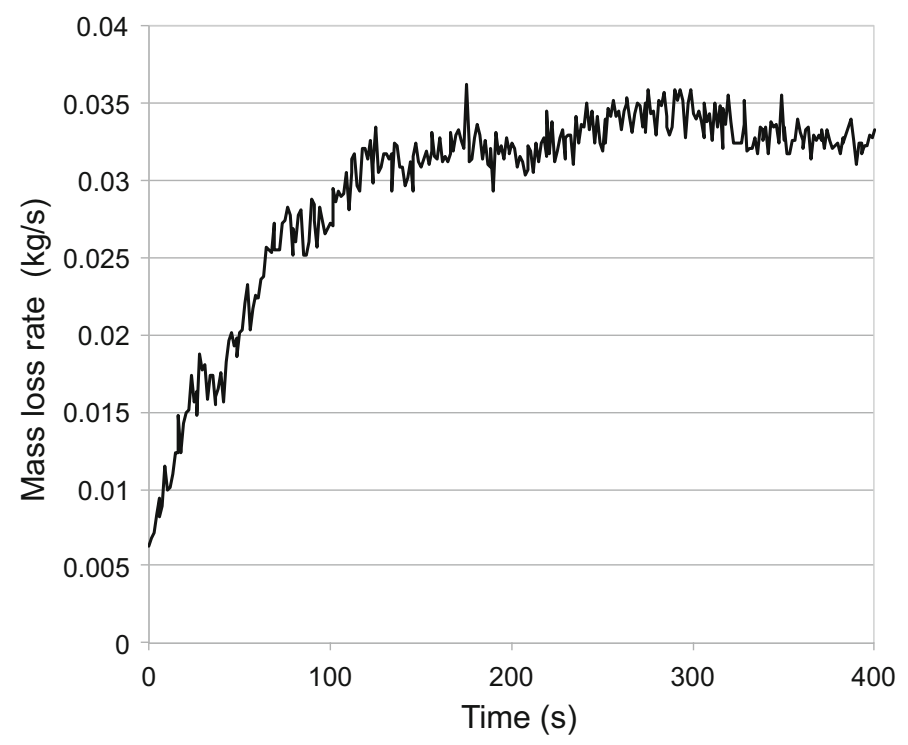
Figure 5. Mass loss rate from the experiment given to the partici-
pants. 
In the original experiment temperature measurements were made with thermocouples. In addition to these measurements the participants were also asked to present results on heat flux, visibility and gas velocity through openings. Participants were assumed to be familiar with measurements and calculations of heat flux, visibility and temperature, as these are used as criteria when performing performance based design according to the Swedish building codes [13]. Furthermore, it is often recommended to study gas velocities through openings in order to check if the results in a simulation is reasonable and that was why it was included as an output that the participants were asked to deliver.

The vast majority of the participants indicated at first contact that they used FDS 5, and to facilitate the comparison of results and rule out differences in outcome depending on type of FDS version it was decided that the participants would use FDS 5. There are different versions of FDS 5, and in the instructions it was indicated that version 5.5.3 was preferred and should be used if possible. More detailed information about the given conditions and the task is available in the thesis [11].

The simulation task differs in some aspects from a normal performance based fire safety design. Fire engineers normally do not have access to the same detailed information as in this simulation task; furthermore, the fire is usually specified in a different way. In Sweden the fire is most often specified with a HRR growth and maximum HRR as specified in the recommendation to the building code [13]. In this case the participants were given a mass loss rate; however, the mass loss rate relates directly to the HRR so it was assumed to be rather straightforward to use and not cause any problems.

\section{Results and Analysis}

This results and analysis section is divided into two parts Inputs and Outputs, in order to identify the variation itself and possible reasons for the variation.

\subsection{Inputs}

3.1.1. Geometry All the participants represented the geometry according to the instructions. There were however differences in how the ground floor was treated, three participants (A, E and $\mathrm{H}$ ) removed it while the others included it in the simulation. Turbulence and the gas flow around the building depended on whether and how the ground floor was taken into account and how the environment around the building was modelled. Removing parts of the building may be associated with risks of modelling flows through the exterior openings incorrectly. One reason to simplify the geometry is that fewer cells are required and the computation time is reduced thereby. There were also differences in how the domain and the meshes was setup (see Table 1).

3.1.2. Building Material The participants received information that the walls were made of $0.3 \mathrm{~m}$ thick Leca blocks with a cement-based coating ( $5 \mathrm{~mm}$ thick), and the floors and ceilings were made of $0.2 \mathrm{~m}$ thick concrete slabs. Additionally, it 


\section{Table 1}

Summary of Number of Meshes, Cell Size and the Total Number of Cells for the Participants

\begin{tabular}{lcccr}
\hline Participant & $\begin{array}{c}\text { Number of } \\
\text { meshes }\end{array}$ & $\begin{array}{c}\text { Cell size close } \\
\text { to fire }(\mathrm{m})\end{array}$ & $\begin{array}{c}\text { Cell size not } \\
\text { close to fire }(\mathrm{m})\end{array}$ & Total number of cells \\
\hline A & 3 & 0.1 & 0.1 & $1,321,920$ \\
B & 4 & 0.1 & 0.1 & $1,641,600$ \\
C & 1 & 0.1 & 0.1 & $2,016,000$ \\
D & 4 & 0.1 & 0.2 & 360,000 \\
E & 4 & 0.05 & 0.05 & $3,419,040$ \\
F & 2 & 0.1 & 0.1 & $1,399,000$ \\
G & 2 & 0.1 & 0.1 & 511,040 \\
H & 4 & 0.1 & 0.1 & \\
\hline
\end{tabular}

was described that the interior surfaces were sooty at the start of the test. Tables 2 and 3 shows how the participants chose to specify the walls, ceiling and floors. When more than one material is given, the wall was created of multiple materials where the first is on the inside of the wall.

No material specific data are given for participant $A$ and $G$ in Tables 2 and 3 because they used inert walls and adiabatic materials, respectively. These are basically opposites in terms of heat loss. Adiabatic walls will result in no heat loss, which is not considered realistic in this case. Participants $E$ and $F$ did not specify the emissivity for the materials, which means that the default value (0.9) in FDS is used [14]. All participants, with the exception of A and G, specified the thickness of the material on the SURF-line (specification of boundaries) in the input file. Participant B, C and D, used $0.3 \mathrm{~m}$ thick walls consisting of a material to represent the Leca block walls. Participant E, F and H, used a $0.30 \mathrm{~m}$ thick material to represent the Leca block walls and also added a $5 \mathrm{~mm}$ thick layer in order to represent the cement-based coating. The thicknesses of the building components as

\section{Table 2}

\section{Summary of Material Properties Used in Walls by the Participants}

\begin{tabular}{llllll}
\hline Participant & \multicolumn{1}{c}{ Material } & $\begin{array}{c}\text { Specific heat } \\
(\mathrm{J} / \mathrm{Kg} \mathrm{K})\end{array}$ & $\begin{array}{c}\text { Density } \\
\left(\mathrm{kg} / \mathrm{m}^{3}\right)\end{array}$ & $\begin{array}{c}\text { Conductivity } \\
(\mathrm{W} / \mathrm{mK})\end{array}$ & Emissivity \\
\hline $\mathrm{A}$ & $I N E R T$ & - & - & - & - \\
$\mathrm{B}$ & Leca & 1.0 & 725 & 0.2 & 0.7 \\
$\mathrm{C}$ & Leca & 1.05 & 650 & 0.2 & 0.9 \\
$\mathrm{D}$ & Leca & 1.05 & 650 & 0.205 & 0,95 \\
$\mathrm{E}$ & Concrete/leca & $1.04 / 1.0$ & $2280 / 650$ & $1.8 / 0.2$ & $-/-$ \\
$\mathrm{F}$ & Concrete/light weight concrete & $1.04 / 1.0$ & $2280 / 500$ & $1.8 / 0.15$ & $-/-$ \\
$\mathrm{G}$ & ADIABATIC & - & - & - & - \\
$\mathrm{H}$ & Calcium silicate/Bricks & 1.25 to $1.55^{\mathrm{a}} / 0.82$ & $720 / 1500$ & $0.12 / 0.37$ & $0.83 /-$ \\
\hline
\end{tabular}

a The value is ramped from $1.25\left(\mathrm{~T}=20^{\circ} \mathrm{C}\right)$ to $1.55\left(\mathrm{~T}=600{ }^{\circ} \mathrm{C}\right)$ 


\section{Table 3}

Summary Material and Material Properties Used in Floors and Ceiling Used by the Participants

\begin{tabular}{llcccc}
\hline Participant & Material & Specific heat $(\mathrm{J} / \mathrm{Kg} \mathrm{K})$ & Density $\left(\mathrm{kg} / \mathrm{m}^{3}\right)$ & Conductivity $(\mathrm{W} / \mathrm{mK})$ & Emissivity \\
\hline A & INERT & - & - & - & - \\
$\mathrm{B}$ & Concrete & 1.04 & 2280 & 1.8 & 0.7 \\
$\mathrm{C}$ & Concrete & 0.88 & 2300 & 1.7 & 0.9 \\
$\mathrm{D}$ & Concrete & 1.04 & 2280 & 1.8 & 0.95 \\
$\mathrm{E}$ & Concrete & 1.04 & 2280 & 1.8 & - \\
$\mathrm{F}$ & Concrete & 1.04 & 2280 & 1.8 & - \\
$\mathrm{G}$ & ADIABATIC & - & - & - & - \\
$\mathrm{H}$ & Concrete & 0.9 & 2300 & 1.63 to $0.45^{\mathrm{a}}$ & \\
\hline
\end{tabular}

a The value is ramped from $1.63\left(\mathrm{~T}=0{ }^{\circ} \mathrm{C}\right)$ to $0.45\left(\mathrm{~T}=1300{ }^{\circ} \mathrm{C}\right)$

\section{Table 4}

Summary of Fuel Parameters Used by the Participants

\begin{tabular}{lcccccc}
\hline Participant & Fuel & $\begin{array}{c}\text { Specified } \\
\Delta \mathrm{H}_{\mathrm{c}}(\mathrm{kJ} / \mathrm{kg})\end{array}$ & $\begin{array}{c}\text { Resulting } \\
\Delta \mathrm{H}_{\text {eff }}(\mathrm{kJ} / \mathrm{kg})\end{array}$ & IDEAL & $\begin{array}{c}\text { CO-yield } \\
(\mathrm{kg} / \mathrm{kg})\end{array}$ & $\begin{array}{c}\text { Soot-yield } \\
(\mathrm{kg} / \mathrm{kg})\end{array}$ \\
\hline A & Propane & $44,500^{\mathrm{a}}$ & 47,281 & $-^{\mathrm{a}}$ & $0.008^{\mathrm{a}}$ & $0.015^{\mathrm{a}}$ \\
$\mathrm{B}$ & Heptane & 44,600 & 44,600 & - & 0.01 & 0.037 \\
$\mathrm{C}$ & Heptane & 41,200 & 39,856 & TRUE & 0.01 & 0.037 \\
$\mathrm{D}$ & Heptane & 44,000 & 44,000 & - & 0.008 & 0.015 \\
$\mathrm{E}$ & Heptane & - & 45,533 & - & 0.006 & 0.015 \\
F & Heptane & 44,600 & 44,600 & - & 0.006 & 0.015 \\
$\mathrm{G}$ & Heptane & - & 45,533 & - & 0.006 & 0.015 \\
$\mathrm{H}$ & Heptane & - & 45,533 & - & 0.006 & 0.015 \\
\hline
\end{tabular}

a Incomplete code was specified, which resulted in that the default fuel propane was used; however, the values that participant A specified corresponds to heptane

${ }^{b}$ Resulting heat of combustion obtained from the FDS output file

specified on the OBST-line (specification of obstructions) in FDS were adapted to the cell size by all the participants.

All participants, with the exception of $A$ and $G$, specified the thickness of the floor and ceiling on the SURF-line to $0.2 \mathrm{~m}$. Regarding heat transfer through the material, participant $\mathrm{C}$ entered BACKING = 'INSULATED' while participants E used BACKING = 'EXPOSED'. The other participants did not specify backing type which means that the default value BACKING = 'VOID' [14] were used in those cases.

3.1.3. Fire Source The participants got the information that the fuel was heptane; they also got the size of the pan and the mass loss rate over time (see Fig. 5). All participants, except participant A, entered the fuel composition as the number of carbon and hydrogen atoms corresponding heptane. Participant A left out a "\&" 
sign which meant that the code was incomplete and FDS used the default fuel (propane) instead of heptane. Table 4 presents the different participants inputs for fuel, carbon monoxide fraction, soot fraction, heat of combustion and if the heat of combustion was ideal or not. If the user does not specify a value to IDEAL the default value FALSE will be used, this means that the effective heat of combustion should be stated as heat of combustion. Three of the four participants entered a heat of combustion that corresponds to the ideal value without entering IDEAL $=$ TRUE. This means that the FDS does not calculate the effective heat of combustion, but assumes that combustion is complete, which results in that these participants simulated a fire where too much energy per kilogram of fuel was released. Conversely, one participant stated the effective value of the heat of combustion and specified IDEAL $=$ TRUE, which resulted in that too little energy per kilogram of fuel was used in the simulation. In the four simulations where heat of combustion was not specified, FDS calculated a resulting heat of combustion. In order to compare the different simulations, the resulting heat of combustion obtained from the FDS output files is presented in Table 4.

The participants got the information that the fire source consisted of a circular pan with a diameter or $800 \mathrm{~mm}$ that was raised $250 \mathrm{~mm}$ above the floor. All participants adapted this surface to a square, to fit the cubic cells, with an area of $0.49 \mathrm{~m}^{2}$ as shown in Table 5. Two different methods were used to define the HRR, either a heat release per unit area (HHRPUA) or mass loss rate per unit area (MLRPUA). In order to ease the comparison is the maximum mass loss rate for each participant presented in Table 5 .

All participants placed the burner on top of a box. The other sides of the burner were defined as inert by participants A, E, F, G and $\mathrm{H}$, as adiabatic by participant $\mathrm{C}$, as steel by participant $\mathrm{B}$ and as concrete by participant D. All participants used RAMP (i.e. the HRR was time dependent) to simulate the fire growth. Participant $\mathrm{C}$ used three different parts of the burner, which had the same maximum HRR but different growth rates.

3.1.4. Weather Conditions The participants were given detailed information about the initial conditions and weather conditions as described above. The fact that the

\section{Table 5}

\section{Summary Burner Parameters Used by the Participants}

\begin{tabular}{lcccc}
\hline Participant & Area $\left(\mathrm{m}^{2}\right)$ & Cells over the fuel surface & MLRPUA $\left[\mathrm{kg} /\left(\mathrm{s} \mathrm{m}^{2}\right)\right]$ & HRRPUA $\left(\mathrm{kW} / \mathrm{m}^{2}\right)$ \\
\hline A & $0.7 \times 0.7$ & 49 & 0.068 & - \\
B & $0.7 \times 0.7$ & 49 & 0.035 & - \\
C & $0.7 \times 0.7$ & 49 & - & 1516 \\
D & $0.7 \times 0.7$ & 49 & - & - \\
E & $0.7 \times 0.7$ & 196 & 0.07 & 2294 \\
F & $0.7 \times 0.7$ & 49 & - & - \\
G & $0.7 \times 0.7$ & 49 & 0.0716 & - \\
H & $0.7 \times 0.7$ & 49 & 0.067 & \\
\hline
\end{tabular}




\section{Table 6 \\ Summary of the Initial Conditions and Weather Conditions Used by the Participants}

\begin{tabular}{lcccc}
\hline Participant & Account of wind & Ambient temperature $\left({ }^{\circ} \mathrm{C}\right)$ & Indoor temperature $\left({ }^{\circ} \mathrm{C}\right)$ & Humidity $(\%)$ \\
\hline A & No & -8.5 & -3 & 90 \\
B & No & -8.5 & -3 & 90 \\
C & Yes & -8.5 & -3 & 90 \\
D & Yes & -8.5 & -3 & 90 \\
E & No & -8.5 & -8.5 & 90 \\
F & Yes & -8.5 & -3 & 90 \\
G & Yes & -8.5 & -3 & 90 \\
H & Yes & -3 & -3 & 90 \\
\hline
\end{tabular}

indoor and outdoor temperatures differed was taken into account by six of the participants. The inputs used by the participants is summarised in Table 6.

Three participants (F, G and $\mathrm{H}$ ) modelled the wind with vectors, participant $\mathrm{C}$ used a dynamic pressure and participant $\mathrm{D}$ used a surface with an entering flow of with a certain speed to model the wind. Participant A, B and E did not model the wind. Many of the participants commented in the follow-up survey that modelling wind was new to them and difficult. A positive aspect is the awareness that the wind can affect the result and that it is not obvious to ignore. However, it is not clear if it is wise to model the wind when some participants in the follow up survey mentioned it as difficult and also inappropriate to do in FDS.

\subsection{Outputs}

Results acquired from the participants' output files are presented in this section.

\subsubsection{Mass Loss Rate and Heat Release Rate The experimentally measured mass} loss rate was given to the participants as a part of the instructions to the simulation task; however, when looking at the resulting mass loss rate that the participants got in their simulations there are large variations. The resulting mass loss rates are, as well as the experimentally measured mass loss rate, included in Fig. 6 (left). It appears that participant $\mathrm{A}, \mathrm{E}, \mathrm{G}$ and $\mathrm{H}$ are relatively close to each other and the given mass loss rate; however, participant B, C, D and F deviates from these.

The main reason to why participants $\mathrm{B}$ and $\mathrm{C}$ received a mass loss rate of half of the value in the experiment is that the mass loss rate had not been adapted after the size of the pan, which was about $0.5 \mathrm{~m}^{2}$. Regarding participants $\mathrm{D}$ and $\mathrm{F}$, which were closer to the mass loss rate in the experiment, but still had a significant deviation, the deviations can be explained by the assigned values in the input file to calculate the heat release rate. Participant D and F used HRRPUA as input (see Table 5) and the conversion into mass loss rate was done with the effective heat of combustion (see Table 4), which lead to errors being introduced. A more reasonable way to replicate the experimental values would be to use MLRPUA, which a majority of the participants did. The main reason to why 

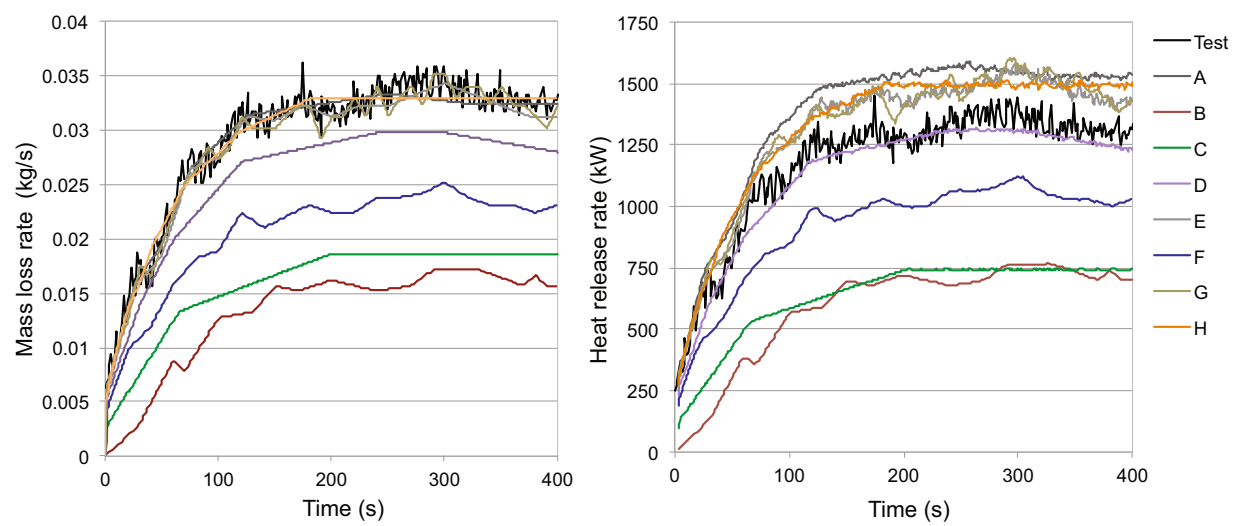

\section{Figure 6. Resulting mass loss rate (left) and heat release rate (right) in the simulations.}

some used HRRPUA instead of MLRPUA was probably that they are more familiar with HRRPUA.

The experimental HRR that is presented in Fig. 6 (right) is only an estimate, which is based on the mass loss rate, a combustion efficiency of 0.9 and heat of combustion of $44,600 \mathrm{~kJ} / \mathrm{kg}$ in table 3-4.14 in the SFPE Handbook [15]. There is nothing that ensures that combustion efficiency was 0.9 in the test, so the HRR that is presented in Fig. 6 (right) is only intended to give an indication of the HRR in the test. Even so, it is interesting that four of the participants, who were close in regard to the mass loss rate (see Fig. 6), are over predicting the HRR. A common feature amongst these four participants is that they did not specify a heat of combustion, and the resulting effective heat of combustion value (see Table 4) is higher than reference values specified in the literature [15], and this could explain the higher HRRs.

The differences in the description of the fuel and the burner among the participants were relatively large, which also had consequences for the mass loss rate and HRR. That several of the participants made mistakes are somewhat surprising as it is well-known that the fire characteristics is one of the most important parameters in fire modelling; therefore, it seems reasonable to double check it for any mistakes.

3.2.2. Temperature Temperature measurements are presented as temperature profiles (after $250 \mathrm{~s}$ ) as well as the increase in temperature over time for the top measurement point in each room in Figs. 7, 8 and 9. The temperatures calculated by participant $\mathrm{G}$ is almost $300 \mathrm{~K}$ higher than the other participants in all measurement points. This severely affects the temperature scale in the figures that makes it hard to study out the variation between the rest of the participants; therefore, the results from participant $\mathrm{G}$ is only included in the temperature profile graphs. The reason for the higher temperatures is that participant $G$ used adiabatic walls. This 

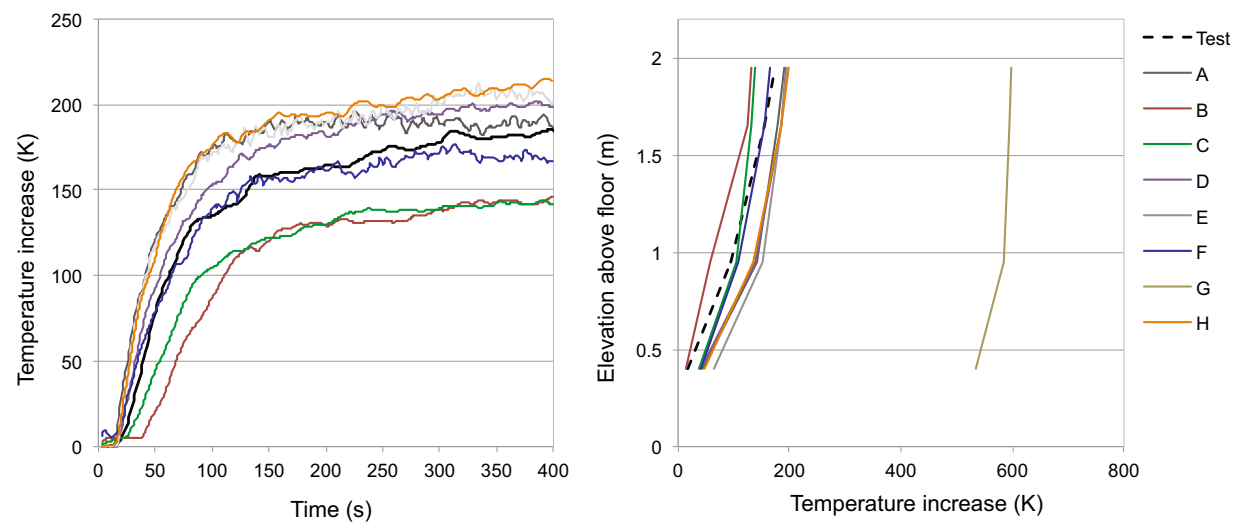

Figure 7. Temperature rise as a function of time (left) and temperature profile (right) in room 1.
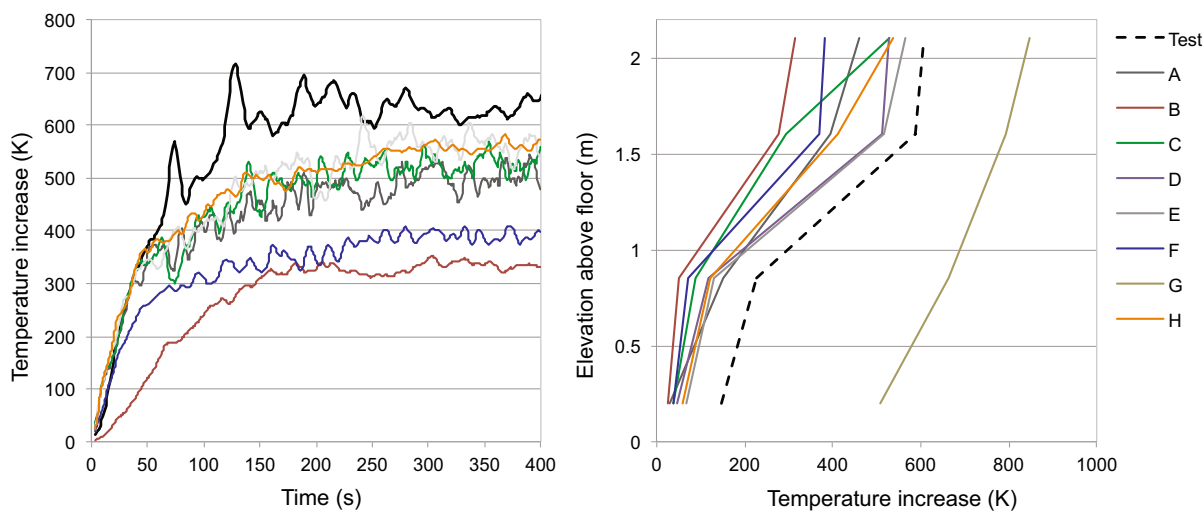

\section{Figure 8. Temperature rise as a function of time (left) and tempera- ture profile (right) in room 2.}

illustrates that the heat loss to the boundaries are an important parameter that can have a large effect on the results if modelled incorrectly.

Participant $\mathrm{C}$ lacked the top measurement point in room 2 and 3 in the input file, and is therefore not included in the right graphs in Figs. 9 and 10. The data presented in Figs. 7, 8 and 9 is a sliding average of $6 \mathrm{~s}$.

All the participants except participant A used thermocouples in FDS to record the temperature. Thermocouples have a higher thermal inertia than gas thus the increases in temperature will be slower, this means that fluctuations are not registered to the same extent when a thermocouple is used as measurement device. However, this effect is small and there is no notable difference between $\mathrm{A}$ and the other participants, which can be ascribed to this.

The comparison between the participants shows that the participants that used a lower HRR also measured lower temperatures than the others. This is obvious 

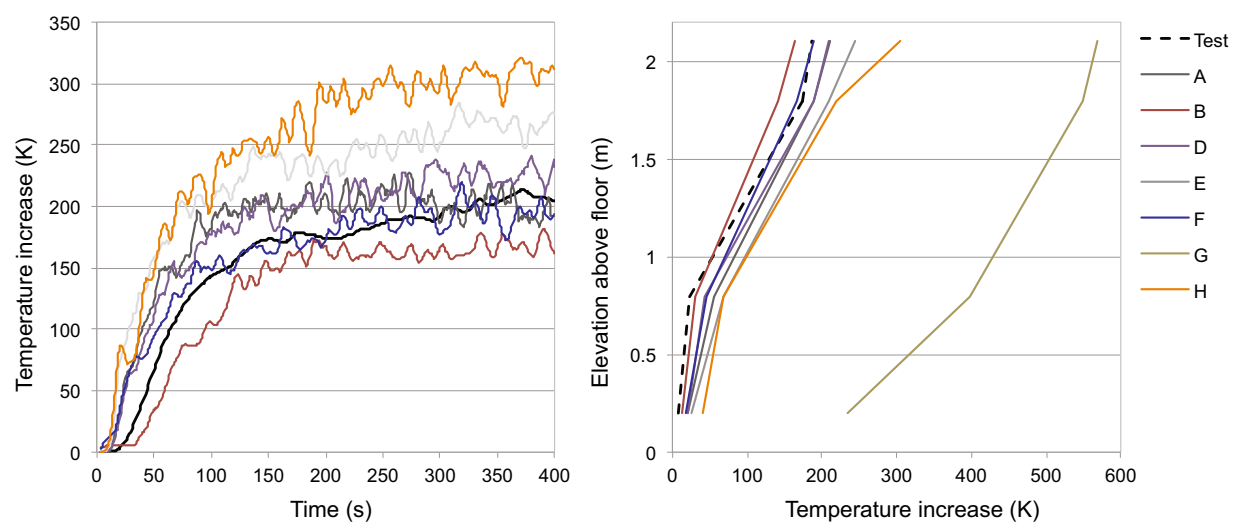

Figure 9. Temperature rise as a function of time (left) and temperature profile (right) in room 3.
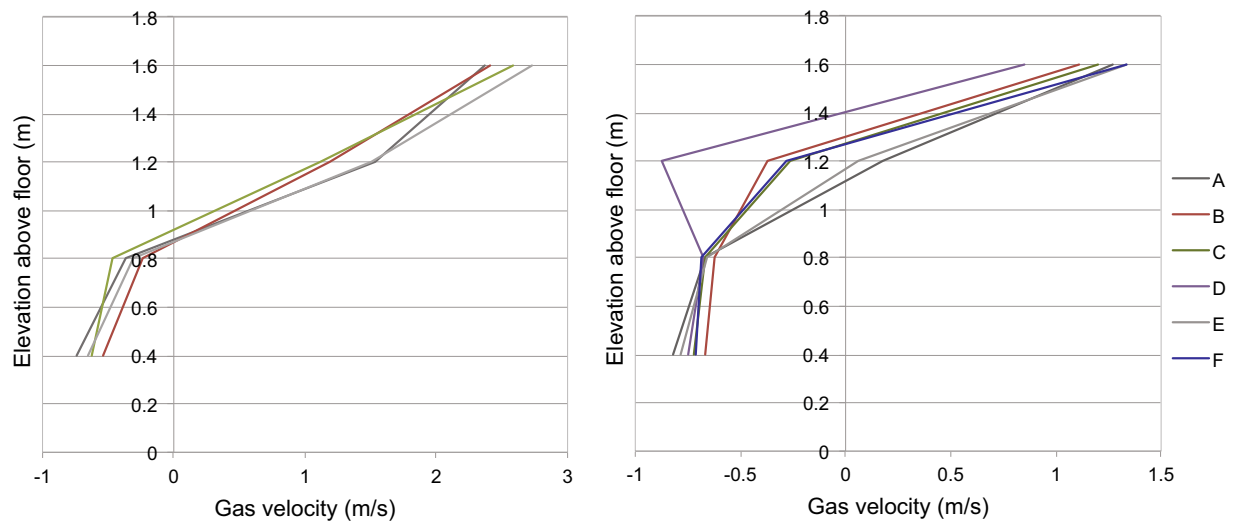

Figure 10. Velocity profiles in opening B (left) and D (right).

because the temperature depends on the amount of energy released. In addition, participants A, D, E and $\mathrm{H}$, which had fairly similar mass loss rate and HRR (see Fig. 6) also measured relatively similar temperatures, even though they had differences in regard to the thermal properties of the walls, ceiling and floor. It should be recognized that when the heat release rate was well defined by the participants, temperature predictions rather close to the experimental values were made.

There is an inconsistence with regard to the correspondence between the experimental data and the results of the simulations in room 2 compared to room 1 and room 3. The experimentally measured temperature is higher in the fire room (room 2), compared to the simulation results, than in the adjacent rooms. The reason for this is that the radiative heat flux effects the temperature measurements in a way in the experiment that is not modeled in the simulations. In the adjacent rooms the effect of radiative heat flux is much smaller and consequently is the measured temperature much closer to temperature of the smoke. 
The variation in temperature between the participants in room 2 was about $300 \mathrm{~K}$ (excluding participant $\mathrm{G}$ ). This means that the lowest recorded temperature increase is about $45 \%$ lower than the highest recorded this is a big difference; however, still significantly less than the differences in the Scottish study [8].

\subsubsection{Other Parameters Not Measured in the Experiment The participants were} asked to present results on visibility, heat flux to a given target and gas velocities through two openings. These quantities were not measured in the experiment; however, included in order to study if there were any variations in how these were calculated. These three quantities were considered to be quantities that are usually of interest in fire safety design and the users should be familiar with the concepts and how they are calculated.

The participants were asked to measure the visibility at $1.8 \mathrm{~m}$ above the floor in the centre of room 1, 2 and 3. All the participants used the output VISIBILITY in the measurement. Six of the participants chose to measure at a single point. Participant B performed a volume measurement; thus, only over a single cell which, corresponds to a point measurement. Only participant F did a volume measurement of several cells around the point of interest. Important fuel parameters in the visibility calculation are heat of combustion and soot yield, which are presented in Table 4.

Due to the large variation in the mass loss rate, and the relationship between it and the visibility, it was expected that there would be large variations in the resulting visibility; however, this was not the case. An example of the visibility results are presented in Table 7.

Regarding the heat flux the participants were asked to measure the incident radiation to the centre of the ceiling in the room 1 and to the floor in room 2 and room 3. The participants used different quantities to measure the heat flux. All participants indicated an index of orientation (IOR) of $3(+$ or -$)$, which indicates a measuring direction in the z-direction. However, participant $\mathrm{C}$ used a positive IOR value in Room 1, which means that the heat flux leaving the ceiling was recorded. Half of the participants used the default value (104) for the number of angles and the default radiation fraction of 0.35 (see Table 8). The others chose to expand the number of radiation angles within a range of 300 to 2000. Only two

\section{Table 7}

\section{Summary of the Time to 10 and $5 \mathrm{~m}$ Visibility in Room 1}

\begin{tabular}{lcc}
\hline Participant & Time to $10 \mathrm{~m}$ visibility (s) & Time to $5 \mathrm{~m}$ visibility (s) \\
\hline A & 30 & 55 \\
B & 50 & 65 \\
C & 35 & 40 \\
D & 30 & 45 \\
E & 25 & 40 \\
F & 35 & 55 \\
G & 30 & 45 \\
H & 25 & 40 \\
\hline
\end{tabular}




\section{Table 8}

Summary of the Participants' Choice of Radiation Angles, Radiative Fraction and Quantity

\begin{tabular}{lccl}
\hline Participant & Number of angles & Radiative fraction $(-)$ & \multicolumn{1}{c}{ Quantity } \\
\hline $\mathrm{A}$ & 104 & 0.35 & RADIATIVE HEAT FLUX \\
$\mathrm{B}^{\mathrm{b}}$ & 1040 & 0.305 & GAUGE HEAT FLUX \\
$\mathrm{C}$ & 104 & 0.35 & RADIATIVE HEAT FLUX \\
$\mathrm{D}$ & 104 & 0.35 & RADIATIVE HEAT FLUX GAS \\
$\mathrm{E}$ & 1000 & 0.35 & INCIDENT HEAT FLUX \\
$\mathrm{F}$ & 2000 & 0.33 & RADIATIVE HEAT FLUX \\
$\mathrm{G}^{\mathrm{b}}$ & $300^{\mathrm{a}}$ & 0.35 & GAUGE HEAT FLUX \\
$\mathrm{H}$ & 104 & 0.35 & RADIATIVE HEAT FLUX \\
\hline
\end{tabular}

${ }^{\text {a }}$ NMIEANG $=45$ was stipulated. The default value is 15

b The radiation meter had an initial temperature of $-3^{\circ} \mathrm{C}$

participants $\mathrm{B}$ and $\mathrm{F}$ chose to change default value of the radiation fraction. A reason that a majority of the participants did not increase the number of radiation angles could be either that the calculation time increases significantly or that to the default value was deemed to be sufficient. In the follow up survey a majority of the participants mentioned that the heat flux is seldom calculated with FDS. Most likely, hand-calculations are more common method for radiative heat flux calculations. Nevertheless, it is striking that a total of four different measurement functions were used for the same measurement (see Table 8).

The different measurement quantities used in this part of the simulation task makes it difficult to compare the results. The heat flux recordings at each measurement point after $250 \mathrm{~s}$ are summarised in Table 9. The values correspond to sliding averages over $6 \mathrm{~s}$.

The participants were asked to record the horizontal gas velocity in opening B and D (see Fig. 10) at four heights in each opening. The quantity that each participant selected for each opening is presented in Table 10. The velocity in the $\mathrm{x}$-direction is obtained by using U-VELOCITY, and V-VELOCITY will give the

\section{Table 9}

\section{Summary of the Participants' Results in the Heat Flux Calculations}

\begin{tabular}{lccc}
\hline Participant & Ceiling room $1\left(\mathrm{~kW} / \mathrm{m}^{2}\right)$ & Floor room $2\left(\mathrm{~kW} / \mathrm{m}^{2}\right)$ & Floor room $3\left(\mathrm{~kW} / \mathrm{m}^{2}\right)$ \\
\hline A & 1.6 & 8.2 & 0.5 \\
B & 2.2 & 7.3 & 0.5 \\
C & $0.01^{\mathrm{a}}$ & 4.6 & 0.4 \\
D & 2.4 & 8.9 & 1.0 \\
E & 5.5 & 7.1 & 1.0 \\
F & 1.0 & 6.4 & 0.4 \\
G & 36.7 & 80.4 & 26.5 \\
H & 1.8 & 12.7 & 0.9 \\
\hline
\end{tabular}

\footnotetext{
a Participant $\mathrm{C}$ did set $\mathrm{IOR}=+3$, which means that the radiation is measured from and not toward the ceiling
} 


\begin{tabular}{lcr}
$\begin{array}{l}\text { Table } 10 \\
\text { Quantities Used by the Participants" to Measure Gas Velocity }\end{array}$ \\
\hline Participant & Quantity opening B & Quantity opening D \\
\hline A & V-VELOCITY & U-VELOCITY \\
B & V-VELOCITY & U-VELOCITY \\
C & V-VELOCITY & U-VELOCITY \\
D & U-VELOCITY & U-VELOCITY \\
E & V-VELOCITY & U-VELOCITY \\
F & U-VELOCITY & U-VELOCITY \\
G & VELOCITY & VELOCITY \\
H & VELOCITY & VELOCITY \\
\hline
\end{tabular}

velocity in the y-direction. If only VELOCITY used the overall speed will be recorded, which is always positive.

The results of the participants' gas velocity measurements in opening B and D are presented with velocity profiles after $250 \mathrm{~s}$ (see Fig. 10). Participants G and H measured the overall speed and not the horizontal as requested, these are therefore not presented in Fig. 10. Participants D and F measured, unlike other participants, the velocity horizontally along opening $\mathrm{B}$ and not through it, their results are therefore left out in Fig. 10 (left). However, the results in opening B are similar for the four participants that measured it as was intended. The differences are larger in the opening $\mathrm{D}$. One factor that could possibly affect the gas velocity is the wind and how it was modelled; still, it was done in several different ways, which makes it difficult to see any connections. The two participants that modelled the wind in the same way cannot be compared since one measured the overall speed and not the horizontal.

It was surprising that half of the participants had problems with the recoding the gas velocities when the gas flows in openings is something that generally is recommended to check in a simulation [16]. These errors may be due to unfamiliarity with how to record gas velocities, that the instructions were not read properly or that the instructions were perceived as unclear.

\section{Discussion and Conclusions}

Based on the presented results it can be concluded that even if the input data is relatively well defined, the results differ significantly between various participants. In the previously Scottish study [8] it was claimed that estimates associated with fire are difficult to perform and that it will result in variation in the final result between participants. This study shows that large differences can occur in a priori modeling even for a well-defined case, and this is also something that has been found in similar studies in other engineering fields [7].

There are several reasons that may have contributed to the variation in the participants' results. These reasons can be grouped into the following four categories: 
- Different assumptions

- Mistakes

- Insufficient knowledge about FDS.

- Insufficient knowledge about fire dynamics.

The first category, "Different assumptions", is natural in fire safety engineering. Fire is a complicate phenomenon and there is often not a single answer to a problem even in the well-defined situation in the simulation task studied in this work. For instance, when looking at established literature on the radiative fraction of heptane different answers will be found; therefore, it is natural that different designers will assume different values for inputs to their calculations. The degree of variation caused by assumptions made by the participants in this study is considered to be rather small; however, it could possibly be larger in other cases, e.g. if less information was given about the fuel the participants would have needed to make more assumptions that might have increased the variation more.

The second category, "Mistakes", refers to that mistakes were most likely made due to the fact that the quality control was insufficient and the underlying reason for that were that the participants did not receive any financial compensation. Consequently, they might not have had the possibility to prioritize the task, which meant that they could not spend as much time to double-check the inputs and results as closely as they wished. This category includes the incidences found with forgotten or misplaced data points and faulty measurement directions. These errors are probably not due to ignorance and would probably not happen if the task had been performed more carefully.

The third category, "Insufficient knowledge about FDS", refers the fact that the simulation task was different from a normal day-to-day task. Some of the participants stated in the follow-up survey that they were not accustomed with all the measurement devices and quantities that were asked for, and this has probably contributed to the variation. Furthermore, some participants pointed out that more simplifications are usually done in real design project and that the input is scarcer. However, it should be an advantage to have access to more data and it is somewhat illogical to think that more information would contribute to a larger variation in the participants' results. Furthermore, several of the participants hinted that there is a big difference between following the recommendations for performance-based design in Sweden [13] and reproducing an experimental test. This is a rather peculiar remark because the only thing that is stated in the recommendations that would affect the simulation task is the standardized fuel.

The final category, "Insufficient knowledge about fire dynamics", is considered to be the most worrisome. The variation in the results can to a large degree be explained by differences in HRR, and it is possible that a lack of fundamental knowledge in fire dynamics can explain why some participants did an incorrect assessment of the HRR and the mass loss rate. The fire growth rate and maximum HRR is now given in recommendations to the Swedish building code, however, if there is a problem with the knowledge in fire dynamics then it will possibly affect other areas of fire safety design than the HRR construction. It is a serious issue for fire protection engineering, which more and more is based on 
advanced computational tools, if fundamental knowledge about the phenomena modeled is lacking. This stresses the need for continuous education and the use of simple and transparent methods (like hand-calculation methods) in order to understand the fundamentals of complex fire dynamics problems.

It is important to stress that small variations in principle are inevitable in the fire safety design process and that it is not necessarily a problem. However, this work focuses on one part ("Simplify problem and setup fire model") of the modeling process as presented in Fig. 1, and it is shown that the differences between modelers can be more than $50 \%$ when it comes to the calculation of temperature increase. This is much more than the model uncertainty that can be expected in various types of fire models, which can be as low as $5 \%$ to $20 \%$ [4, 17] depending on model and scenario. The numbers should not be compared directly, however, they obviously imply that the uncertainty in the result is more associated with the designer than with the fire model used. Looking at more parts of the fire safety design process (e.g. if the participants could feely chose fire model, see Fig. 1), as was done in the Scottish study [8], will most likely increase the variation.

It is considered important to focus on the different parts of the modeling process separately in future studies of user effects in fire safety engineering calculations. Because if it can be determined how large variation that may be expected from each part, recommendations can be specific targeted towards parts that contribute to a large part of the total variation between different designers. As an example the results from this study indicates clearly stated recommendations on heat release rates (e.g. growth rates and maximum values) could reduce the possible variation amongst practitioners. This is something that has been done in recent revisions of the building regulations in both Sweden and New Zealand.

This is a limited study in a single country, further similar studies are recommended in order to narrow down the uncertainties that exist in the fire safety design process. It is believed that the result from this type of study can be used when prioritizing the type of guidelines and recommendations for performancebased fire safety engineering that should be developed.

\section{Open Access}

This article is distributed under the terms of the Creative Commons Attribution 4.0 International License (http://creativecommons.org/licenses/by/4.0/), which permits unrestricted use, distribution, and reproduction in any medium, provided you give appropriate credit to the original author(s) and the source, provide a link to the Creative Commons license, and indicate if changes were made.

\section{References}

1. Olenick SM (2003) An updated international survey of computer models for fire and smoke. J Fire Prot Eng 13:87-110. doi:10.1177/1042391503013002001

2. FireFoam (2017) https://github.com/fireFoam-dev. Accessed 14 July 2017 
3. Floyd J, Forney G, Hostikka S, Korhonen T, McDermott R, McGrattan K, Weinschenk C (2013) Fire Dynamics Simulator technical reference guide - vol 3: validation. NIST Special Publication 1018, National Institute of Standards and Technology, Gaithersburg

4. McGrattan K, Peacock R, Overholt K (2014) Validation of fire models applied to nuclear power plant safety. Fire Technol. doi:10.1007/s10694-014-0436-z

5. Lamb AR (2004) Computer analysis: avoiding the 'black box' syndrome. In: Proceedings of ICE, pp. 134-139

6. Lauridsen K, Christou M, Amendola A, Markert F, Kozine I, Fiori M (2001) Assessing the uncertainties in the process of risk analysis for chemical establishments: part II. In: Towards a safer world, european conference on safety and reliability. ESREL

7. Fröderberg M, Thelandersson S (2015) Uncertainty caused by variability in preliminarily structural design of buildings. Struct Safety 52B:183-193. doi:10.1016/j.strusafe.2014.02.001

8. Rein G, Torero-Cullen J, Jahn W, Stern-Gottfried J, Ryder NL, Desanghere S, Lazaro M, Mowrer F, Coles A, Joyeux D, Alvear D, Capote JA, Jowsey A, Abecassis-Empis C, Reszka P (2009) Round-robin study of a priori modelling predictions of the Dalmarnock Fire Test One. Fire Safety J 44(4):590-602. doi:10.1016/j.firesaf.2008.12.008

9. DBH (2014) C/VM2 verification method: framework for fire safety design for New Zealand building code clauses C1-C6 protection from fire. Department of Building and Housing, Wellington

10. Boverket (2013) The Swedish National Board of Housing, Building and Planning's general recommendations on the analytical design of a building's fire protection, BBRAD. Boverket, Karlskrona

11. Ekholm M (2015) Jämförelse av FDS-simuleringar (Comparison of FDS simulations). Division of fire Safety Engineering, Lund University, Report 5488, Lund (in Swedish)

12. Johansson N, Svensson S, van Hees P (2015) A study of reproducibility of a full-scale multi-room compartment fire experiment. Fire Technol 51:645. doi:10.1007/s10694-0140408-3

13. Boverket (2013) Boverkets ändring av allmänna råd (2011:27) om analytisk dimensionering av byggnaders brandskydd, BFS 2013:12, BBRAD 3. Karlskrona, Sweden (in Swedish)

14. McGrattan K, McDermott R, Hostikka S, Floyd J (2010) Fire Dynamics Simulator (version 5) user's guide, NIST Special Publication 1019-5. NIST Building and Fire Research Laboratory, Gaithersburg

15. SFPE (2002) SFPE Handbook of Fire Protection Engineering, 3rd edn. National Fire Protection Association Inc, Quincy

16. BIV (2013) CFD-beräkningar med FDS (CFD calculations with FDS). BIV - Swedish SFPE chapter (in Swedish)

17. Johansson N, Svensson S, van Hees P (2015) An evaluation of two methods to predict temperatures in multi-room compartment fires. Fire Safety J 77:46-58. doi:10.1016/ j.firesaf.2015.07.006 